\title{
T-shaped microstrip patch antenna for RF communications
}

\author{
Sehabeddin Taha Imeci ${ }^{1 *}$, Haris Ačkar ${ }^{1}$, Faruk Matoruga ${ }^{1}$ \\ ${ }^{1}$ Department of Electrical Engineering, International University of Sarajevo, Bosnia
}

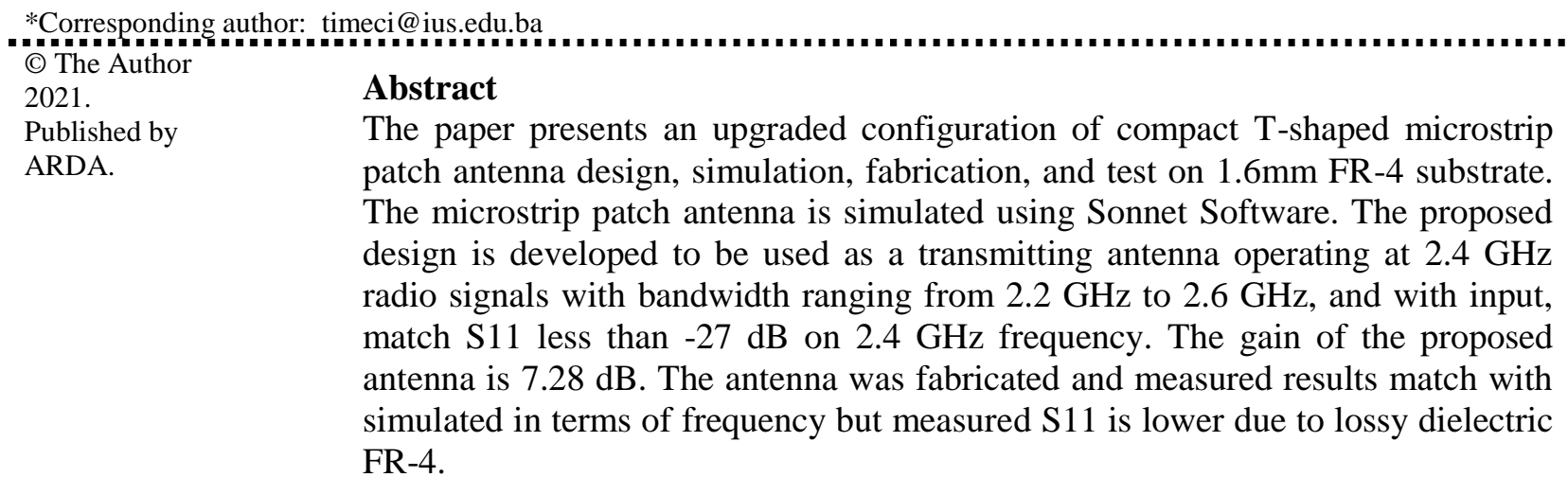

Keywords: Microstrip antenna; T-shaped; FR-4; Gain

\section{Introduction}

In the modern IoT world, when we have a lot of smart devices for remote sensing and home automation, in some cases we need to have small suitable antenna for transmitting data to those smart home devices. Most of those devices are used to make our life easier. A lot of papers are introduced and the authors are talking about Wireless Sensor Network (WSNs) operating at $2.4 \mathrm{GHz}$ have turned out to be the one of the most exciting areas of research in the past few years $[1,2,3]$. Besides that, there are many interesting Microstrip antennas and array designs at 2.4Ghz, for Low Energy Bluetooth or RFID [4, 5], but in this paper the focus will be on simple design of transmitting antenna for $2.4 \mathrm{GHz}$ radio, which is widely used for remote sensing and remote control. In the literature a lot of different antenna designs for $2.4 \mathrm{GHz}$ can be found $[6,7]$. The main focus for $2.4 \mathrm{GHz}$ antenna is that we wanted to make some small contribution for these widely used antennas. The goal was to use basic T-shaped inset fed patch antenna and to change geometry in order to have higher gain and bandwidth to make possible to use this type of antenna in multiple channel communications like WiFi or Low Energy Bluetooth, which is highly used is this era of IoT devices.

In section 2, detailed antenna design and description of the design can be found. Section 3 consists of simulation and experimental results and results comparison. At the end of this paper one can find conclusion, suggestions for future work and references.

To have a successful patch antenna design, it is important to achieve various performances by simulation results. Planar electromagnetic simulation software, called Sonnet Suites was used in this paper. To have a proper deign, first thing is impedance and antenna bandwidth. Input impedance was maintained by formulations on various antenna geometries and Network Analyzer is used to measure this parameter [8].

\section{Microstrip antenna calculations}

1) There are many calculations found in literature to design microstrip patch antennas. One of the most common equations for the width of the antenna is given as follows:

This work is licensed under a Creative Commons Attribution License (https://creativecommons.org/licenses/by/4.0/ ) that allows others to share and adapt the material for any purpose (even commercially), in any medium with an acknowledgement of the work's authorship and initial publication in this journal. 


$$
W=\frac{1}{2 f_{r} \sqrt{\mu_{0} \varepsilon_{r}}} \sqrt{\frac{2}{\varepsilon_{r}+1}}=\frac{v_{0}}{2 f_{r}} \sqrt{\frac{2}{\varepsilon_{r}+1}}
$$

Where $v_{0}$ is the free-space velocity of light.

2) The effective dielectric constant of microstrip patch antenna is given as:

$$
\varepsilon_{e f f}=\frac{\varepsilon_{r}+1}{2}+\frac{\varepsilon_{r}-1}{2}\left[1+12 \frac{h}{W}\right]^{-1 / 2}
$$

3) Expression of extension of length is given by:

$$
\Delta L=h \frac{\left(\varepsilon_{\text {reff }}+0.3\right)\left(\frac{W}{h}+0.264\right)}{\left(\varepsilon_{\text {reff }}-0.258\right)\left[\frac{W}{h}+0.8\right]}
$$

4) Length of patch is given by:

$$
L=\frac{1}{2 f_{r} \sqrt{\varepsilon_{r e f f}} \sqrt{\mu_{0} \varepsilon_{0}}}-2 \Delta L
$$

Many techniques have been presented in order to reduce the size of microstrip patch antennas at fixed operating frequency. The antenna design proposed in this paper uses an inset microstrip-line feed. The insetfed is used to reduce antenna size in order to have a smaller antenna and to operate at fixed frequency [9].

The antenna design is based on FR-4 substrate material of $1.6 \mathrm{~mm}$ thickness. The proposed design is shown in Fig. 1. The antenna has an inset fed, and small metal areas around $\mathrm{T}$ shape. Those areas are used to ensure that the antenna has enough radiation power on resonant frequency, and better current distribution, that can be seen in Fig. 1, in the third section of the paper. Also, these small metal areas are added in order to increase the bandwidth of the antenna. This type of antenna is used for easier change of channels on $2.4 \mathrm{GHz}$ radio signal. For example, if the data rate is $1 \mathrm{Mbps}$, channel spacing will we $1 \mathrm{MHz}$. With bandwidth of $40 \mathrm{MHz}$, it is possible to control a large number of remote devices. This antenna design is very simple and can be easily reproduced in any CAD software [10].

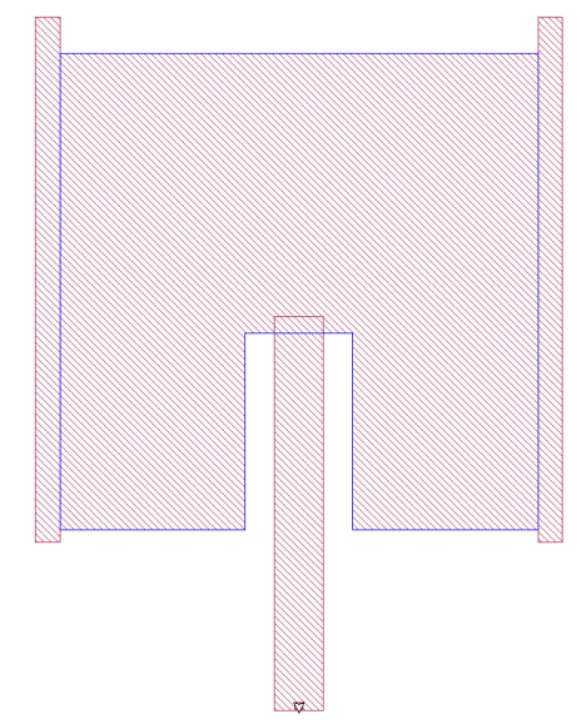

Figure 1. Top view of the antenna design

\section{Results}

This antenna is designed and analyzed using the Sonnet Software. In Fig. 2, the gain pattern of the antenna is shown. Horizontal polarization of the antenna has a $7.28 \mathrm{~dB}$ gain at the resonant frequency and cross polarization has the level of $-40 \mathrm{~dB}$ as seen in Fig. 2. 
Measured gain patterns of the proposed antenna at $2.4 \mathrm{GHz}$ are presented in Fig. 3. According to simulated results, gain of proposed antenna at $2.4 \mathrm{GHz}$ is $7.28 \mathrm{~dB}$ at horizontal polarization. The measurement results are different because of reasons which will be explained later in the paper. According to measurements results presented in Fig. 3, gain of fabricated antenna at $2.4 \mathrm{GHz}$ is $2.95 \mathrm{~dB}$ at horizontal polarization.

In Fig. 4, it is shown that the input match is $-27 \mathrm{~dB}$ at the resonant frequency of the antenna. The input match is less than a $-10 \mathrm{~dB}$ in the frequency range between $2.2 \mathrm{GHz}$ and $2.6 \mathrm{GHz}$. In the same figure it is presented measured vs. simulated S11 graph for the proposed antenna. As we can see from the graph, both simulated and measured curves have similar resonant frequency but with different input matches.

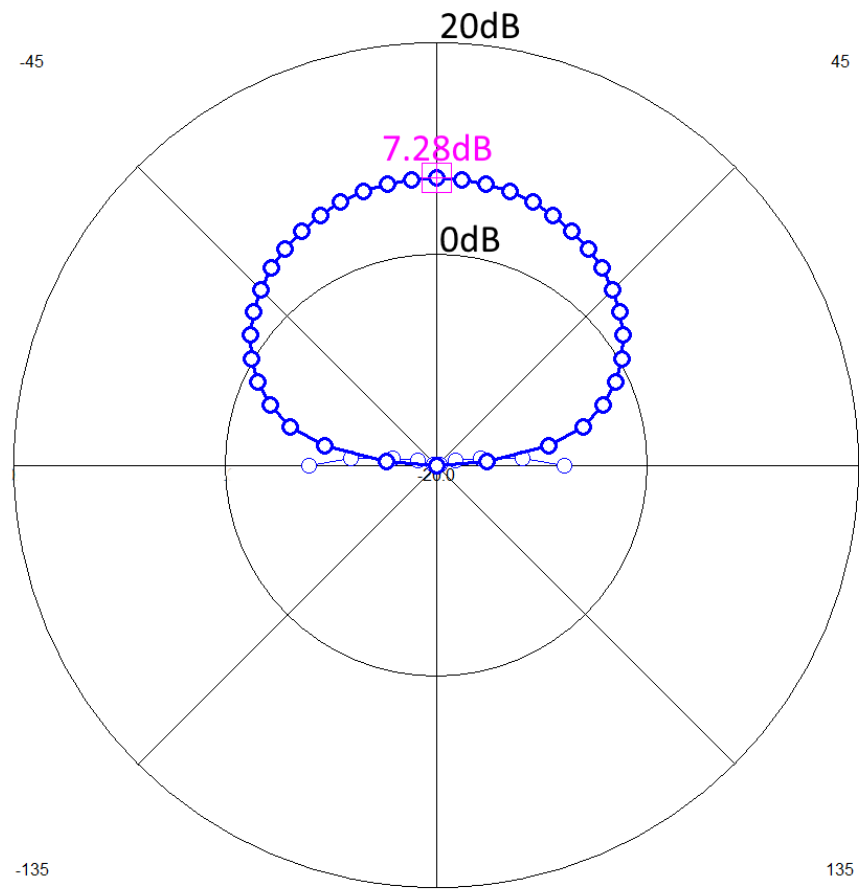

Figure 2. Gain pattern of the proposed antenna design at $2.4 \mathrm{GHz}$

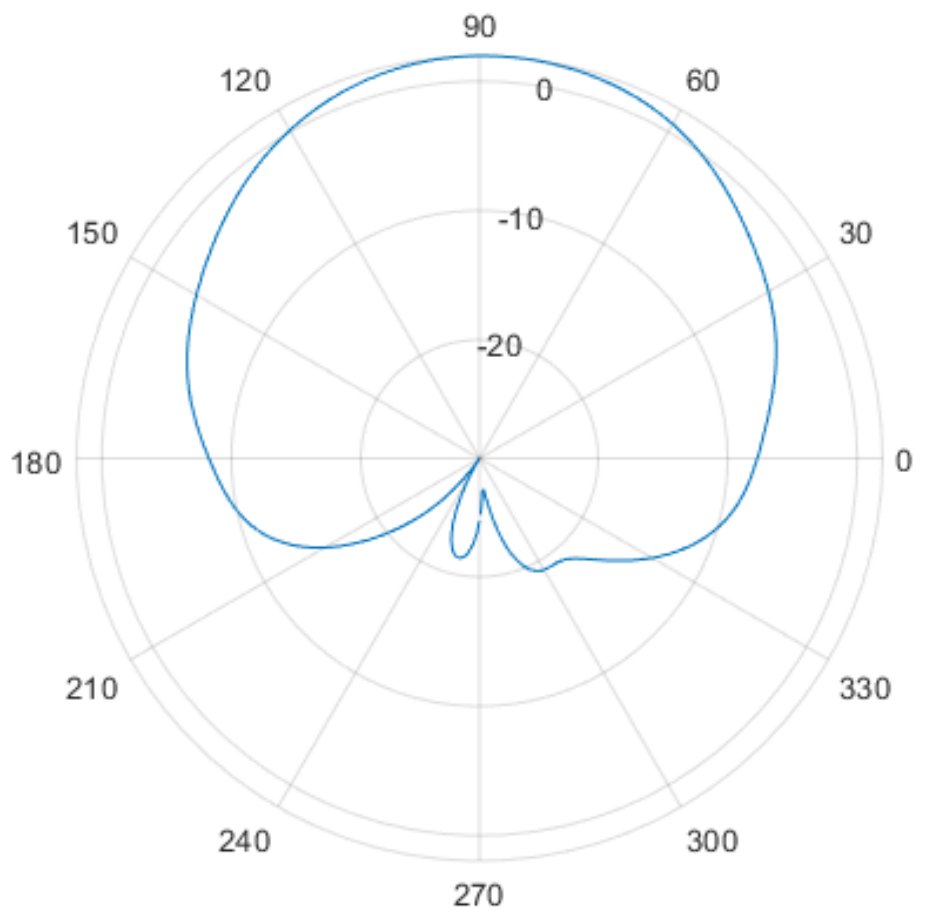

Figure 3. Measured gain pattern of the proposed antenna design at $2.4 \mathrm{GHz}$ 


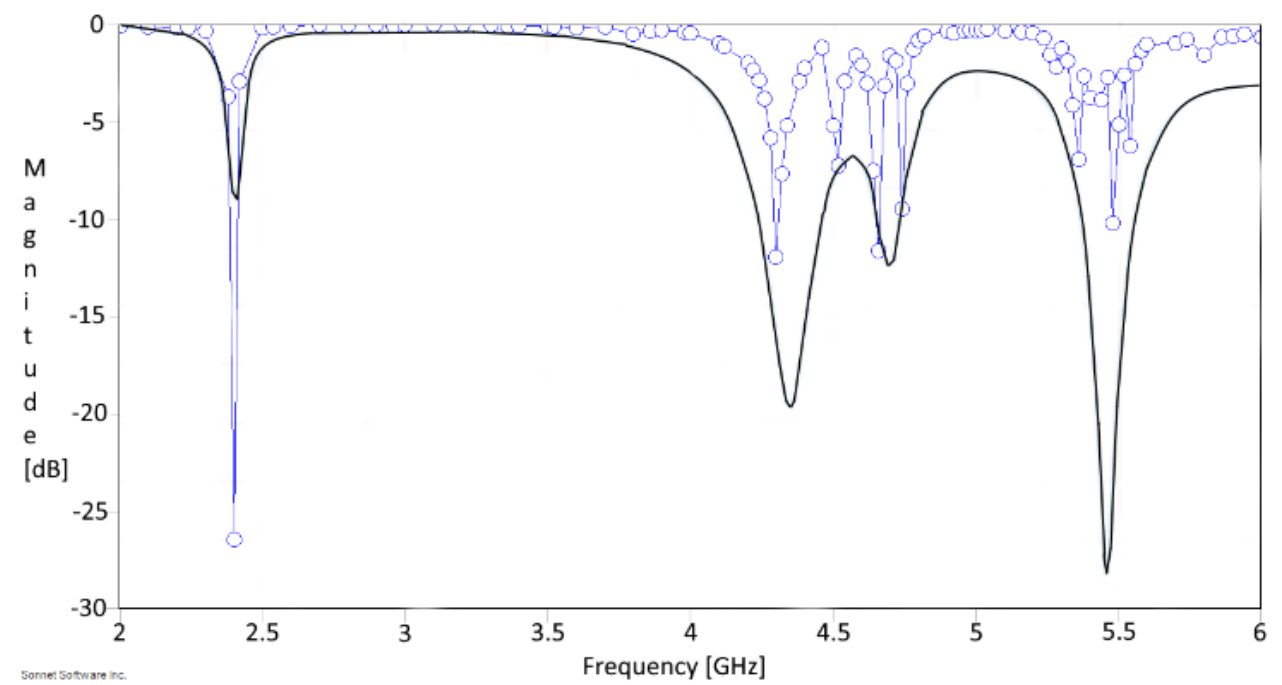

Figure 4. Simulated (bule) and measured (black) input match of proposed antenna from $2 \mathrm{GHz}$ to $6 \mathrm{GHz}$

In the figure above, measured S11 graph (black colored) for the proposed antenna is depicted from $2 \mathrm{GHz}$ to 6 $\mathrm{GHz}$. From the measurement results can be concluded that according to measurement results this antenna can be used on different resonant frequencies. The main idea was to have simple antenna for $2.4 \mathrm{GHz} \mathrm{RF}$ communication, because of this idea, gain measurements were not conducted on higher frequencies. The resonant frequency of $2.4 \mathrm{GHz}$ was local minimum, according to this measurement graph.

Based on simulated and measured results from Fig. 4, it is possible to see that, the input match on $2.4 \mathrm{GHz}$ frequency is $-9 \mathrm{~dB}$ in measured graph; on the other hand in simulated one we can see $-27 \mathrm{~dB}$ on $2.4 \mathrm{GHz}$. Also, at higher frequencies, we can see that we have local minimums on same spots on both graphs, but input match on measured and simulated graphs have amplitude differences due to simulation errors and lossy dielectric. Fig. 5 has the current distribution of the antenna, and it is possible to see that the radiation of the antenna comes mostly from the center of the $\mathrm{T}$ shape, and also from the additional metal regions on the left and right side of $\mathrm{T}$ shape.

The small metal parts on left and right hand sides are added in order to increase the antenna gain. Using Sonnet software, with multiple simulations, its discovered that highest current density is on edges, and in order to increase the density the metal parts are added. Fig. 6 has the fabricated antenna inside anechoic chamber. The anechoic chamber was used to measure antennas radiation pattern.

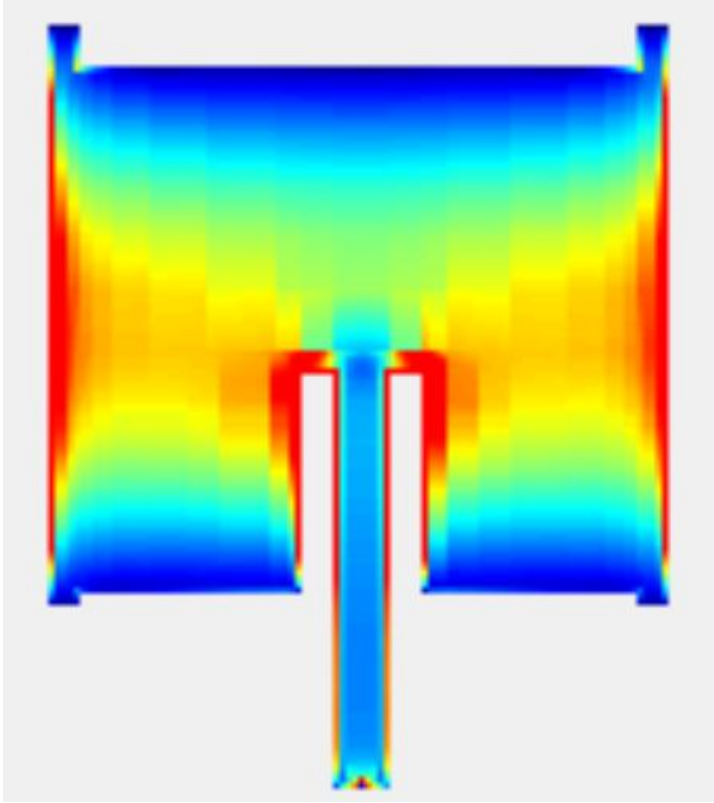

Figure 5. Current distribution of proposed antenna design at $2.4 \mathrm{GHz}$ 


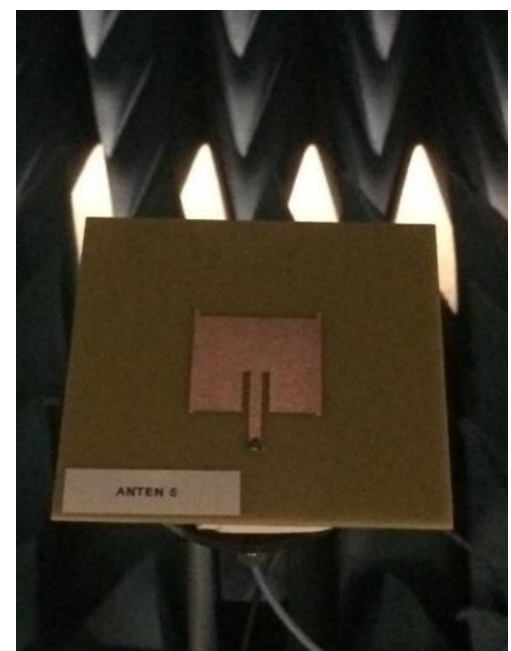

Figure 6. Fabricated antenna inside anechoic chamber

\section{Conclusion}

In this paper, an improved T-shaped inset-fed microstrip patch antenna for $2.4 \mathrm{GHz}$ radio communication is presented. The antenna has simple design, similar to antenna presented in [1], and it can be easily drawn in any CAD Software. The antenna is designed on a FR-4 substrate, which has $1.6 \mathrm{~mm}$ thickness. Because of the fact that FR-4 is a standard substrate for most of the printed circuit boards, this antenna design can be easily implemented on any printed circuit boards. The Sonnet simulations reveals that the designed patch antenna is capable of operating between $2.4 \mathrm{GHz}$ and $2.6 \mathrm{GHz}$. Measurement data are a little bit different from simulation because of lossy dielectric.

\section{Acknowledgements}

Authors would like to thank the support of all staffs of the Department of Electrical and Electronics Engineering, International University of Sarajevo. Special thanks are due for the Aselsan, where measurement results were conducted.

\section{References}

[1] H. Ačkar, S. I. Taha, "Inset fed T-shaped patch antenna for $2.4 \mathrm{GHz}$," in International conference of Electrical Engineering and Computer Science, Sarajevo, Bosnia and Herzegovina, pp. 50-52, 2019.

[2] R. S. Ransing, M. Rajput, "Smart home for elderly care, based on Wireless Sensor Network," in 2015 International Conference on Nascent Technologies in the Engineering Field (ICNTE), pp. 1-5, 2015.

[3] B. L. R. Stojkoska, K. V. Trivodaliev, "A review of Internet of Things for smart home: Challenges and solutions," Journal of Cleaner Production, vol. 140, 1454-1464, 2017.

[4] A. Buffi, A. A. Serra, P. Nepa, G. Manara, "A focused planar microstrip array for $2.4 \mathrm{GHz}$ RFID readers," IEEE Transactions on Antennas and Propagation, vol. 58, no. 5, 1536-1544, 2010.

[5] A. Sarma, K. Sarmah, K. K. Sarma, "Low return loss slotted rectangular microstrip patch antenna at 2.4 GHz," in 2015 2nd International Conference on Signal Processing and Integrated Networks (SPIN), pp. 35-39. IEEE, 2015.

[6] Y. S. Khraisat, "Design of 4 elements rectangular microstrip patch antenna with high gain for $2.4 \mathrm{GHz}$ applications," Modern applied science, vol. 6, no 1, 68, 2012.

[7] F. Yang, X. X. Zhang, X. Ye, Y. Rahmat-Samii, "Wide-band E-shaped patch antennas for wireless communications," IEEE transactions on antennas and propagation, vol. 49, no. 7, 1094-1100, 2001.

[8] R. Garg, P. Bhartia, I. Bahl, A. Ittipiboon, Microstrip Antenna Design Handbook, Artech House, 2001. 
[9] J. G. Joshi, S. S. Pattnaik, S. Devi, M. R. Lohokare, "Bandwidth Enhancement and Size Reduction of Microstrip Patch Antenna by Magnetoinductive Waveguide Loading," Wireless Engineering and Technology, vol. 2011, no. 2, pp. 37-44, 2011.

[10] C. A. Balanis, Antenna Theory: Analysis and Design, Wiley, 2016. 